\title{
COMPARISON OF RESULTS FROM TRANSIT SATELLITE TRACKING
}

\author{
by
}

\author{
James McDonald and Ian M. Whillans
}

(The Ohio State University, Department of Geology and Mineralogy, and Byrd Polar Research Center, 125 South Oval Mall, Columbus, OH 43210, U.S.A.)

\section{ABSTRACT}

Large-scale motions and strain-rates over great distances on polar ice sheets are often obtained from the tracking of Transit (or doppler) satellites. The results of different processing techniques for these tracking data are compared, using some of the data collected on and near Ice Stream C. Reduction is made by using the software packages CALIPER, GEODOP V, MAGNET, and the micro-processor on the Magnavox MX1502 satellite receiver. The orbital data broadcast by the satellites are used, as well as more precise orbits obtained afterward. In addition, calculations are made for single sites individually (point positioning) and for many sites with simultaneous tracking data (network adjustment).

The results agree within the range of known errors associated with the orbits. Earth-based positions (latitude, longitude, ellipsoidal height), based on the broadcast orbits, agree to within $41.1 \mathrm{~m}$. Positions with more precise orbits are within $0.7 \mathrm{~m}$ of one another. Relative positions are best obtained by using network techniques, and these agree with terrestrial survey results within $0.2 \mathrm{~m}$ in horizontal separation for sites $19 \mathrm{~km}$ apart, and are within $4.8 \mathrm{~m}$ in elevation difference. The calculated azimuth differs by $1.5 \mathrm{~m} / 19 \mathrm{~km}$ or $10^{-4} \mathrm{rad}$.

\section{INTRODUCTION}

Velocities and large-scale strain-rates for ice sheets are generally obtained from data on the tracking of Transit (or doppler) satellites (Young 1979, Möller and Gerdau 1981, Drew 1983, Drew and Whillans 1984, Seeber and Hinze 1984, Thomas and others 1984, Lindner and Ritter 1985, Shibuya 1986, Whillans and others 1987). The use of such satellite receivers enables field workers to survey remote points on the ice sheet, far from exposed bedrock. The receivers operate automatically and, at high latitudes, sufficient data for one site can be obtained with only 24 hours' tracking. In addition, rough positions for the receiver can be obtained while in the field if the receiver contains a micro-processor. The use of the Transit positioning system is currently the most practical method for large-scale surveying on ice sheets.

After field work, the positions can be improved by the use of more accurate satellite orbits, better estimates of receiver and satellite errors, tropospheric refraction effects, and data from other satellite receivers that operate at the same time. These post-processing techniques include point positioning and network calculations using either the broadcast or the precise orbits. Furthermore, if the field program includes the simultaneous operation of two or more receivers, it must be appropriately designed in order to obtain the best positional information.

The techniques are separated into categories that depend on the processing of the satellite orbits used and on whether simultaneous data are available from multiple field receivers. The orbits used can be those broadcast by the satellites (broadcast ephemeris), or those obtained later from the U.S. Defense Mapping Agency (precise ephemeris). The broadcast orbits have standard errors of $20-30 \mathrm{~m}$ in the along-track direction (Jenkins and LeRoy 1979) or 5-70 m (root mean square) in all directions (Eisner and others
1982), and the precise orbits have standard errors of $2 \mathrm{~m}$ (Kouba 1983). Relative positions can, however, be better than the orbital uncertainties may suggest, because certain systematic orbital inaccuracies can be corrected if data from two or more receivers are used. Such a multiple-station calculation is termed translocation if the position of one of the receivers is adjusted according to the positional error detected at another simultaneously tracking receiver, but without restricting calculations to mutually tracked passes or parts of passes (Wells 1976). It is termed short-arc calculation if only data from mutually tracked passes are used and if part of the orbit of the satellite is also determined in the solution (Brown 1976). In short-arc calculations it is usual to adjust 3,4 , or 6 orbital parameters. Single-site positions that are processed independently of data from other field receivers are termed point positions. Thus there are three levels of decision: (1) positions can be calculated with data from a single receiver or from multiple receivers working simultaneously in a network; (2) the broadcast or the precise orbits may be used; (3) one of several different software packages may be used.

The objective of this study is to conduct a comparison, using ordinary methods, of the different processing techniques and the different software packages available at the Ohio State University. The question is whether the different software packages or reduction techniques yield significantly different results. In addition, each of the processing techniques and software packages differ in computation cost and in the amount of time required to train operators and process the data. Therefore a method, or combination of methods, is sought that yields adequate results without excessive cost or effort.

The data used are from a field program carried out on the ice streams in West Antarctica. The methods are similar to those used in an earlier field program in Greenland (Drew and Whillans 1984). In Greenland, two sites were selected on bedrock and were occupied for the entire field season. These two sites were used as fixed reference points during network adjustments. For each year, the positions on the ice sheet were referenced to these fixed sites. In this project on the ice streams, the fixed sites are located near the top of very slowly moving ice ridges that lie between the fast-moving ice streams. This adds a further complication, because any errors in the velocity of the fixed sites affect all the referenced velocities. A reason for the present study is to determine the best methods for the reduction of data from ice streams A, B, and C.

\section{PROCEDURE}

In the present study, four software packages are examined. The simplest is the micro-processor in the Magnavox MX1502 receiver, which uses the broadcast orbits and is used here only for point positions. MAGNET and CALIPER are used for both point positions and network adjustments. The most sophisticated package is GEODOP $\mathrm{V}$, which is used for both point positions and network adjustments, and provides the option of using precise orbits. In addition, the distance between two sites on Ice Stream C has been measured by terrestrial techniques and the results 


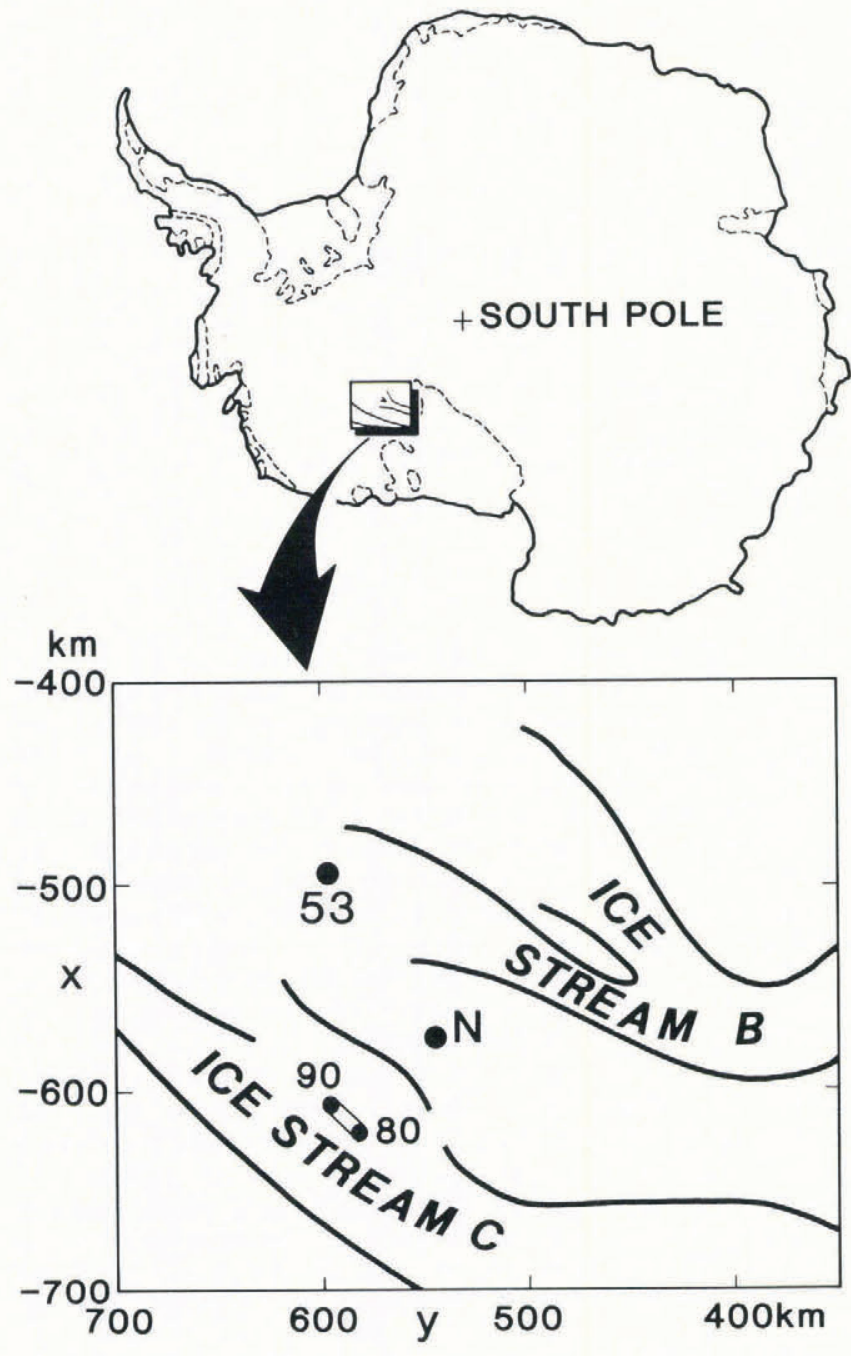

Fig. 1. Location of stations.

can be compared with the results of satellite tracking. It is thus possible to compare the results of each package with one another and with terrestrial survey results.

The program on the ice streams used ten receivers simultaneously, of which two were normally at the reference sites. The present study uses the results of just the four tracking sites shown in Figure 1, and the results from the sites on Ice Stream C for the 1984-85 field season (sites 80 and 90) are discussed. The other two sites (sites 53 and $\mathrm{N}$ ) are used in network adjustments because they refine the satellite orbits.

The results for each software package and technique are compared in Tables I and II. Table I compares the Earth-based coordinates for one of the receivers. These results are relevant if one requires a position that is linked to a global geodetic datum, such as latitude, longitude, or ellipsoidal height. Table II compares the results for relative positions between two of the receivers. Relative positions are more accurate and more relevant to relative motions needed to establish strain-rates. These two calculations are representative of requirements in glaciologic applications; absolute positions are given in Table $\mathrm{I}$, and relative positions are given in Table II.

\section{SOFTWARE PACKAGES}

The most obvious differences between the packages, apart from operational procedure, are in the use of weather data and precise orbits, and (in the case of network adjustments) how many orbital parameters are adjusted.

The weather data (temperature, pressure, and humidity) are relevant because refraction through the troposphere delays the radio signal from the satellite. A special difficulty on polar ice sheets is that usually only the surface meteorological values are available and, because of the prevalent near-surface air-temperature inversion, conditions may be quite different only $100 \mathrm{~m}$ above the surface. Modelling of the troposphere with these packages does not allow for this temperature inversion. Surface temperature and pressure, and a mean value of $62 \%$ relative humidity derived from historical records at Byrd Station, are used. The tropospheric refraction model that is used in CALIPER and GEODOP $\mathrm{V}$ is the Hopfield algorithm. The micro-processor on the MX1502 receiver does not use weather data. MAGNET includes a tropospheric model whose parameters are estimated by using the doppler data, exclusive of meteorological conditions (Ross 1982).

The first software package listed in the tables is that in the micro-processor in the MX1502 satellite receiver. The results are those obtained in the field and calculated by the receivers during tracking. Weather data are not used, and only the orbits broadcast by the satellites can be used. It is by far the easiest package to use. Two-site network adjustments are possible, but have not been attempted.

CALIPER was obtained from EDO-Canada, and version 3.00 , which includes the GP-1s program for the final reductions, is used here. It runs on a micro-computer, works with the broadcast orbits, and accepts weather data. It does point-position calculations as well as network adjustments, using the semi-short-arc method (which adjusts three orbital parameters for each pass). In all network adjustments with CALIPER and other packages, constraints can be placed on certain positions. However, the work reported here was done without constraining any position.

MAGNET is supplied by Magnavox, Advanced Products and Systems Company, and the version used here operates on a mainframe computer. In capability it is similar to CALIPER; MAGNET is also a semi-short-arc method that uses only the broadcast orbits. As noted above, weather data are not used. Both CALIPER and MAGNET are very easy to use.

GEODOP $\mathrm{V}$ is supplied by Dr Jan Kouba (Kouba and Boal 1976, Kouba 1979); it has been altered to run on an IBM mainframe computer by Dr B. Archinal (Archinal and Mueller 1982) and was subsequently modified by one of us (J.McD.) for ease of use by the addition of interactive calling routines. In spite of our efforts at streamlining, GEODOP $\mathrm{V}$ requires a much more knowledgeable operator than the other packages. Our version includes updates from Kouba through January 1986. It can adjust six orbital parameters (full short-arc technique) but is also used here with only three adjusted parameters in order to make it comparable with CALIPER and MAGNET. (These parameters are the mean anomaly, semi-major axis, and orbital inclination, which correspond roughly to along-track height and across-track directions respectively, as used in MAGNET (Ross 1982) and CALIPER (Brunell and others 1982).)

GEODOP $\mathrm{V}$ is the only package available to us that accepts the precise orbits. Precise orbits for satellite Nos 13 and 48 are used here.

\section{POINT OR ABSOLUTE POSITIONS}

Table I shows the calculated Earth-based positions for station 80. The table shows differences from the network adjustment, with six calculated orbital parameters, using the sof tware GEODOP V and precise orbits from two satellites. This technique is reputed to be the best of those used. The coordinate system is the same as for other aspects of the project on ice streams $\mathrm{B}$ and C. Differences parallel to longitude $0^{\circ}$ and $180^{\circ}$ are called $\Delta x$, positive toward Greenwich. Those parallel to longitude $90^{\circ} \mathrm{W}$ and in that direction are designated $\Delta y$, and vertical differences are $\Delta z$. For brevity, only the results for station 80 are shown here. Results for the other stations are similar.

Also shown in the table are formal standard deviations, $\sigma$, and the number of passes used in the calculation. There were 57 passes recorded at site 80 in January 1985, but not all are used by the software packages. Passes may be omitted because they are judged by the package to be too short and to contain insufficient data. In network adjustments, only passes that are tracked and recorded by at 
TABLE I. ABSOLUTE POSITION FOR STATION 80

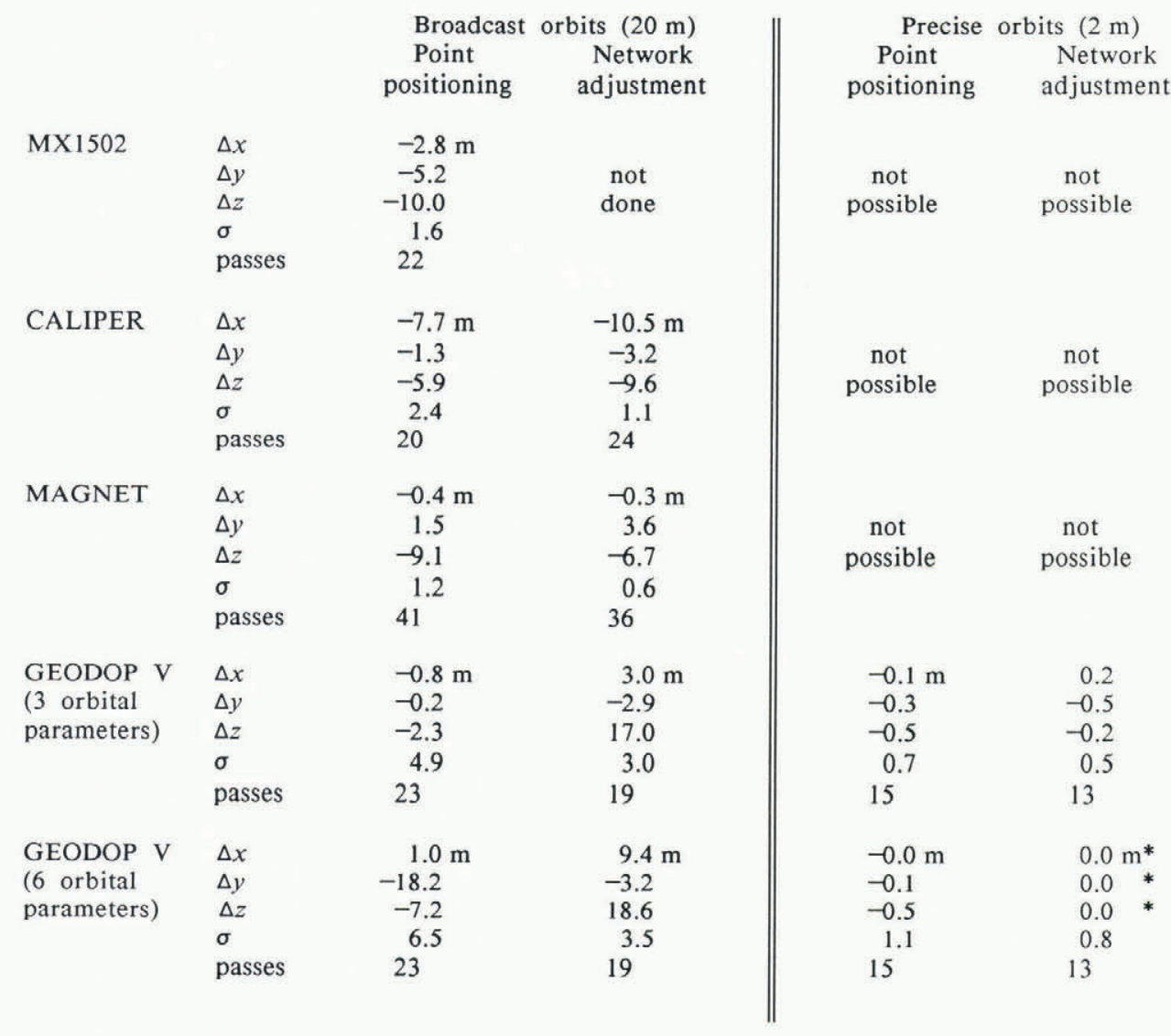

Positions are referenced to the GEODOP position indicated by *. That position is $\mathrm{S}^{\circ} 2^{\circ} 22^{\prime} 04.363^{\prime \prime}$, W1 $36^{\circ} 56^{\prime} 14.93^{\prime \prime}, 463.9 \mathrm{~m}$ above the WGS 72 ellipsoid. Differences $\Delta x$ and $\Delta y$ are horizontal and $\Delta z$ is vertical.

least two receivers are used. When using precise orbits, there is a further restriction to those passes for which the orbits are available. In addition, the receivers at stations 80 and 53 seem to have been recording passes before their oscillators were fully stabilized and the first seven and 13 passes respectively were deleted before use by GEODOP V. CALIPER and MAGNET do not, in ordinary usage, advise the operator about oscillator stability, so those passes have not been removed for these packages. Therefore each reduction technique and software package uses differing numbers of passes.

There is a bias between the broadcast and precise orbits. This arises from the different ways in which the orbits are calculated (Jenkins and LeRoy 1979). The transformation between broadcast and precise orbits could be calculated, but it has not been done. To emphasize the known bias between the two sets of results, double vertical lines separate them in Table I.

Taking orbital uncertainties into account, the results for the Earth-based positions in Table I are all acceptable. Those for ellipsoidal height $(\Delta z)$ are poorest. Horizontal positions differ within $19.7 \mathrm{~m}$, using broadcast orbits and data from single receivers (point positions). The scatter between software packages is slightly improved by calculating all four sites simultaneously in a network adjustment, because certain orbital inconsistencies affect all the packages in the same way. The resulting horizontal positions are within $11.1 \mathrm{~m}$ of one another. The horizontal positions using precise orbits differ within $0.5 \mathrm{~m}$, which is better than expected and maybe fortuitous.

Better agreement among positions using the broadcast orbits may have been expected, considering that orbital errors are common to all software packages and that they work with the same data. However, the criteria for acceptable data differ between packages, which can account for much of the difference. For example, MAGNET used 41 of the 57 available passes, whereas the MX1502 used only 22 of the passes. Thus each of the positions is calculated by using partly different data. Moreover, the distribution of passes (northward- versus southwardtravelling, and passing to the east versus west) is not usually symmetrical, especially in the cases for which a sub-set of the passes is accepted in the solution. This introduces a bias (and often decreases the formal error). Furthermore, the packages adjust orbits with different degrees of freedom. The version of GEODOP $\mathrm{V}$ in the bottom row of the table adjusts six parameters but MAGNET and CALIPER adjust three.

Thus it is not clear whether there is a consistent bias associated with any one technique in obtaining Earth-based coordinates. A much larger study is needed for precise resolution of this issue. It would involve many stations and require only satellite passes that are common to all the software packages in order to ensure strict comparability. The objective here, however, is not to evaluate solution algorithms, but to compare results that would be obtained operationally.

The Earth-based positions displayed in Table I are thus acceptable. The differences are consistent within known orbital errors.

\section{FORMAL ERRORS}

The tables indicate $1 \sigma$ (or one standard deviation) formal errors. The formal error is a measure of the internal consistency of the solution and is often termed precision. It should not be confused with the reliability of the result, or accuracy. Formal errors are available for each coordinate, but in order to make comparison simpler we 
TABLE II. RELATIVE POSITIONS FOR STATIONS 80 AND 90

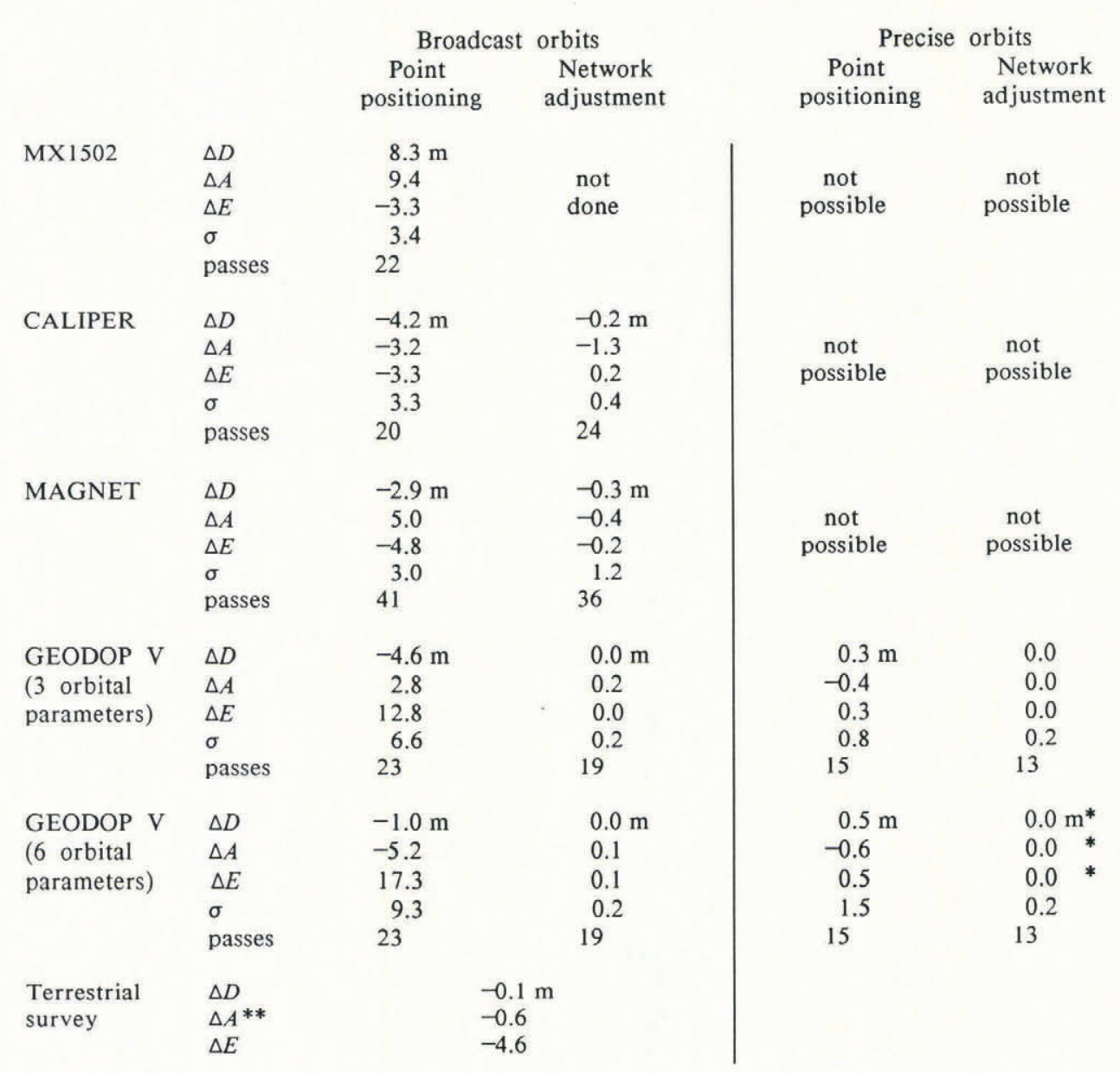

\begin{abstract}
Results are referenced to one obtained by GEODOP as indicated by *. That slope distance is $18549.4 \mathrm{~m}$. The azimuth is $91^{\circ} 19^{\prime} 21^{\prime \prime}$ and the elevation difference is $84.5 \mathrm{~m}$. Discrepancies are for slope distance $\Delta D$, clockwise difference in meters at end of line for azimuth, $\triangle A$, and height discrepancy $\Delta E$, and are referenced to those in the lower right-hand corner.
\end{abstract}

**Because of an error in the conventionally obtained azimuth in 1984-85, this comparison is for surveys conducted in 1985-86.

have presented in Table $I$ the root-mean-square formal error. It is due mainly to the formal standard deviations in the horizontal directions, which are about equal to one another. The formal errors for the vertical position are smaller but, as noted below, they are misleading.

Systematic uncertainties are not included in these formal error estimates. For example, all orbits may be displaced in a consistent direction, and so the calculated position is also displaced in the same way. This is illustrated for GEODOP V in Table $I$ : the same software package used in different ways produces horizontal positions that differ by up to $20.5 \mathrm{~m}$, yet the formal errors are $6.5 \mathrm{~m}$ or less. These variations in position occur because the different processing techniques attribute data inconsistencies to different orbital or positional sources and because the different methods select varying amounts of the data from the field work. Note that the number of passes accepted varies from 41 to 13 . The formal errors can thus be very misleading and they are included in the tables to emphasize that point.

A study in Greenland demonstrates further the problem with formal errors. Drew (1983, table 13) obtained relative vertical velocities of $2 \mathrm{~m} \mathrm{a}^{-1}$ between adjacent sites, with formal errors of about $0.1 \mathrm{~m} \mathrm{a}^{-1}$. (Allowance is made for down-slope motion.) The mass balance of that part of Greenland is near zero (Kostecka and Whillans 1988) and such vertical motion differences are not tenable. In this case, true errors are 20 times the formal error. This demonstrates the caution that should be exercised in using formal errors.

\section{RELATIVE POSITIONS}

Much better accuracy is obtained with relative positioning: distances, height differences, and azimuths between sites 80 and 90 are displayed in Table II. Relative-positioning computations remove many systematic errors in satellite orbits, and ionospheric and tropospheric refraction effects. The simplest procedure is translocation, in which point positions calculated from passes recorded at about the same time (such as those calculated for station 80 in Table I) are differenced. This has been done for the columns labelled "point positioning" in Table II. A better procedure is to consider only those passes that are recorded simultaneously at both sites in network adjustments, which eliminates many common orbital errors. This table includes the distance between receivers, height differences, and a measure of the azimuth of the line between the stations. Results are with reference to the network adjustment by GEODOP $\mathrm{V}$, with precise orbits for two satellites and six adjusted orbital parameters.

As expected, the network adjustments provide more consistent relative positions than point positions. Distances 
compare to within $12.9 \mathrm{~m}$ by differencing point positions (translocation) and to within $0.3 \mathrm{~m}$ in network adjustments.

In the network adjustments it does not matter whether the precise or broadcast orbits are used. This is because many orbital errors are corrected or affect stations in the same way. However, use of the broadcast orbits is simpler and gives more data, because precise orbits are ordinarily provided for just two satellites. For network adjustments, we therefore recommend use of the broadcast orbits.

Relative azimuth and heights are more poorly determined than separation distance. The largest discrepancy in azimuth among the network adjustments is $-1.3 \mathrm{~m} / 19 \mathrm{~km}$ or $1 \times 10^{-4}$, and the largest in elevation difference is $0.2 \mathrm{~m}$, but that is considered fortuitous. Separation distance is considered to be the best-determined parameter, and so glaciologic surveys using Transit receivers are best designed so that the directions to reference sites from field stations are about $90^{\circ}$ apart.

The formal errors in distance are obtained from the variances in the calculated coordinate differences. In the case of network adjustments, covariances reduce the formal error in distance.

Formal errors for the program in southern Greenland are about $0.1 \mathrm{~m}$ using GEODOP V (Drew 1983). For the current Antarctic data they are about $0.2 \mathrm{~m}$, except for the MAGNET network adjustment. Thus the degradation due to the higher latitude of the stations in this program is relatively small.

The results of satellite tracking are also compared with the results of terrestrial surveys. Sites 80 and 90 are within the strain grid on Ice Stream $C$ described by Whillans (1984). Intermediate distances were measured over lengths of about $1000 \mathrm{~m}$, using an AGA model 112 Geodimeter, in December 1983 and December 1985. Each survey was adjusted by the least-squares technique, and the separation between stations 80 and 90 was obtained by interpolation for the time of the satellite tracking discussed here (January 1985). The terrestrially obtained distance should be accurate to about $0.2 \mathrm{~m}$. The height difference, terrestrially obtained in December 1983 by pressure altimeter, is accurate to only $5 \mathrm{~m}$. Errors made in obtaining azimuth by conventional techniques in 1984-85 preclude a meaningful comparison. Azimuths obtained from TRANSIT data can, however, be compared with solar observations for the following year. The solar observations were obtained by using a Kern DKM2 theodolite, following the hour-angle method of Buckner (1984), and are accurate to about $3 \mathrm{~m}$ over the $19 \mathrm{~km}$ separation of stations 80 and 90 . The deviation in azimuth, $\triangle A$, from the GEODOP $\mathrm{V}$ network adjustment with precise orbits for two satellites is only $-0.6 \mathrm{~m}$, which is another fortuitous agreement. Other comparisons between terrestrial surveys and satellite results are poorer for the 1985-86 data than for the 1984-85 data discussed here There is only about half the number of commonly tracked passes in 1985-86 and the network linkage is weaker, which may account for the discrepancies.

The velocities of stations 80 and 90 are $(-0.7,-1.0)$ and $(-5.2,-11.5) \mathrm{m} \mathrm{a}^{-1}$ respectively, for components in $x-$ and $y$-directions. These are obtained from differences between point positions using precise orbits.

\section{CONCLUSIONS}

The various software packages and reduction techniques compute positions that are consistent within known orbital errors. Absolute, or Earth-based, positions compare to within about $30 \mathrm{~m}$ using the broadcast orbits, and to within $2 \mathrm{~m}$ using precise orbits. Relative positions are best determined by network adjustment, or by differences in point positioning obtained from precise orbits. Separation distances agree to within $0.3 \mathrm{~m}$ using network techniques. Azimuths and height differences are less well determined.

All of the network adjustments are about equivalent for the data studied here. If a network adjustment can be made, the use of precise orbits is not necessary. Of the network programs, CALIPER and MAGNET are the easiest to use.

Workers should not be confused by the formal error estimates provided by the software packages. The error estimates provided by (for example) the MX1502 receiver/ processor are very much smaller than the reliability of the position.

For future processing of glaciologic data, we recommend use of GEODOP V (with precise orbits to refine the positions of reference sites), and any of the network-adjustment schemes to determine relative positions. Any degradation in position due to operation at high latitudes seems to be small.

\section{ACKNOWLEDGEMENTS}

We thank P.L. Vornberger for making the leastsquares adjustment of the UPC strain grid. John Bolzan, Clyde Goad, Miriam Jackson, and a referee made helpful suggestions. Henri Ayers of EDO-Canada supplied CALIPER, and Mario Fernandez of Magnavox provided MAGNET. The U.S. Defense Mapping Agency provided the precise ephemerides. Typed by C. Gribbin. Figure by R. Tope. Supported by U.S. National Science Foundation grant DPP-8517590. This is Byrd Polar Research Center contribution No. 631

\section{REFERENCES}

Archinal, B.A., and I.I. Mueller. 1982. A comparison of geodetic Doppler satellite receivers. In Proceedings of the Third International Symposium on Satellite Doppler Positioning. Las Cruces, NM, New Mexico State University. Physical Science Laboratory, 917-935.

Brown, D.C. 1976. Doppler positioning by the short-arc method. In Proceedings of the First International Symposium on Satellite Doppler Positioning, Las Cruces, NM, New Mexico State University. Physical Science Laboratory, 97-140.

Brunell, R.D., R. Malla, I. Fejes, and S. Mihaly. 1982 Recent satellite processing software improvements at JMR. In Proceedings of the Third International Symposium on Satellite Doppler Positioning. Las Cruces, NM, New Mexico State University. Physical Science Laboratory, 247-269.

Buckner, R.B. 1984. A manual on astronomic and grid azimuth. Rancho Cordova, CA, Landmark Enterprises.

Drew, A.J.R. 1983. Glacial movements in Greenland from Doppler satellite observations. Ohio State Univ. Inst. Polar Stud. Rep., 82.

Drew, A.J.R., and I.M. Whillans. 1984. Measurement of surface deformation of the Greenland ice sheet by satellite tracking. Ann. Glaciol., 5, 51-55.

Eisner, A., S.M. Yionoulis, J.A. Platt, R.E. Jenkins, J.C. Ray, and L.L. Pryor. 1982. NOVA-1; the newest TRANSIT satellite (a status report). In Proceedings of the Third International Symposium on Satellite Doppler Positioning. Las Cruces, NM, New Mexico State University. Physical Science Laboratory, 843-862.

Jenkins, R.E., and C.F. LeRoy. 1979. "Broadcast" versus "precise" ephemeris - apples and oranges. In Proceedings of the Second International Symposium on Satellite Doppler Positioning. Austin, TX, University of Texas at Austin. Applied Research Laboratory, 39-62.

Kostecka, J.M., and I.M. Whillans. 1988. Mass balance along two transects of the west side of the Greenland ice sheet. J. Glaciol., 34(116), 31-39.

Kouba, J. 1979. Improvements in Canadian geodetic Doppler programs. In Proceedings of the Second International Symposium on Satellite Doppler Positioning. Austin, TX, University of Texas at Austin. Applied Research Laboratory, 63-82.

Kouba, J. 1983. A review of geodetic and geodynamic satellite Doppler positioning. Rev. Geophys. Space Phys., 21(1), 27-40.

Kouba, J., and J.D. Boal. 1976. Program Geodop. Ottawa, Department of Energy, Mines and Resources.

Lindner, K., and B. Ritter. 1985. Geodätische Arbeiten auf den Filchner-Ronne- und Ekström-Shelfeisen 1979 bis 1982. Polarforschung, 55(1), 1-26.

Möller, D., and H. Gerdau. 1981. Geodetic surveying on the Filchner/Ronne Ice Shelf in the Atka Bay 1979/80. Polarforschung, 51(1), 43-53.

Ross, W.T. 1982. Magnet, Magnavox network adjustment 
post processing software. In Proceedings of the Third International Symposium on Satellite Doppler Positioning. Las Cruces, NM, New Mexico State University. Physical Science Laboratory, 231-245.

Seeber, G. and H. Hinze. 1984. Bestimmung von Gletschereisbewegungen mit Doppler-Satellitenmessungen in der Antarktis. Vermessungswesen, 4, 176-186.

Shibuya, K. 1986. Glacio-geophysical implication of an NNSS positioning in and around Syowa Station, East Antarctica. J. Geodyn., 6(1-4), 327-346.

Thomas, R.H., D.R. MacAyeal, D.H. Eilers, and D.R. Gaylord. 1984. Glaciologic studies on the Ross Ice Shelf, Antarctica, 1973-1978. In Bentley, C.R., and D.E. Hayes, eds. The Ross Ice Shelf: glaciology and geophysics. Washington, DC, American Geophysical
Union, 21-53. (Antarct. Res. Ser., 42.)

Wells, D.E. 1976. Concept of satellite Doppler positioning using translocation techniques. In Proceedings of the First International Symposium on Satellite Doppler Positioning. Las Cruces, NM, New Mexico State University. Physical Science Laboratory, 76-96.

Whillans, I.M. 1984. Ice stream dynamics. Antarct. J. U.S., 19(5), 51-53.

Whillans, I.M., J. Bolzan, and S. Shabtaie. 1987. Velocity of ice streams B and C, Antarctica. J. Geophys. Res., 92(B9), 8895-8902.

Young, N.W. 1979. Measured velocities of interior East Antarctica and the state of mass balance within the I.A.G.P. area. J. Glaciol., 24(90), 77-87. 